\title{
Coronary heart disease
}

National Diabetes Information Clearinghouse (NDIC)

\section{Definitions}

Artery

Defined by National Diabetes Information Clearinghouse (NDIC)

Heart attack

Defined by National Diabetes Information Clearinghouse (NDIC)

Source

National Diabetes Information Clearinghouse (U.S.). (2009). The diabetes dictionary. [Bethesda, Md.]: U.S. Dept. of Health and Human Services, National Institutes of Health, National Institute of Diabetes and Digestive and Kidney Diseases,

National Diabetes Information Clearinghouse.

Heart disease caused by narrowing of the arteries that supply blood to the heart. If the blood supply is cut off, the result is a heart attack. 